\title{
Organic Cultivation of Jasmine and Tea Increases Carbon Sequestration by Changing Plant and Soil Stoichiometry
}

\author{
Weiqi Wang,* Qingwen Min, Jordi Sardans,* Chun Wang, Dolores Asensio, Mireia Bartrons, and Josep Peñuelas
}

\begin{abstract}
Organic cultivation methods would be a good alternative to conventional cultivation, avoiding the use of industrial fertilizer and reducing the risk of eutrophication, but its impacts on soil elemental composition and stoichiometry warrants to be clearly stated. This study was conducted to determine the effects of long-term organic cultivation on soil elemental composition, stoichiometry, and $\mathrm{C}$ storing capacity and $\mathrm{CO}_{2}$ emissions in the plant-soil systems of jasmine (Jasminum spp.) and tea [Camellia sinensis (L.) Ktze.] plantations in Fujian and other regions in China. We examined the impact of organic cultivation on the concentrations, contents and stoichiometric relationships among $\mathrm{C}, \mathrm{N}, \mathrm{P}$, and $\mathrm{K}$. Organic cultivation was associated with lower plant $\mathrm{N}$ and $\mathrm{P}$ concentrations, and $\mathrm{P}$ mineralomasses and with higher total plant $\mathrm{C} / \mathrm{N}, \mathrm{C} / \mathrm{P}, \mathrm{C} / \mathrm{K}$, and $\mathrm{N} / \mathrm{P}$ ratios and higher soil $\mathrm{N}$ and $\mathrm{P}$ concentrations and contents at some depths. Organic cultivation was thus associated with a shift of $\mathrm{P}$ from plants to soil and with a higher nutrient-use efficiency in biomass production, mainly of $\mathrm{P}$. Soil $\mathrm{CO}_{2}$ emissions were higher under organic cultivation, but the soil was able to accumulate more $\mathrm{C}$ with no changes in $\mathrm{C}$ storage in plant biomass, suggesting that organic cultivation could increase the overall $\mathrm{C}$ sequestration, thereby mitigating climate change and enhancing soil nutrient content. Our results thus showed that the organic cultivation of jasmine and tea in Fujian can improve soil fertility and $\mathrm{C}$ accumulation, reduce the use of industrial fertilizers and phytosanitary products, and improve product quality without loss of economical profits.
\end{abstract}

\section{Core Ideas}

- Jasmine and tea cultivation have a long history in Fujian and other regions in China

- We explored their organic cultivation for the future viability of these crops

- Organic cultivation increased nutrient-use efficiency

- Soil was able to accumulate more $\mathrm{C}$ under organic cultivation

- Organic cultivation improved soil fertility without affecting economic profits

\footnotetext{
Published in Agron. J. 108:1636-1648 (2016)

doi:10.2134/agronj2015.0559

Received 17 Nov. 2015

Accepted 23 Feb. 2016

Supplemental material available online

Copyright (C) 2016 by the American Society of Agronomy 5585 Guilford Road, Madison, WI 53711 USA
}

All rights reserved

\author{
HINA is the world's largest producer of tea, with \\ $1.849 \times 10^{6} \mathrm{ha}^{-1}$ of cultivation producing $1.359 \times 10^{6} \mathrm{t}$ \\ of tea annually (You et al., 2013). Tea is an important
} cash crop in the subtropical hilly region of China and is mainly distributed in the red soil area, which is one of the most important continental ecosystems in China (You et al., 2013; Wang et al., 2014). Jasmine tea is unique, and China is the only country that has mastered the critical scenting technologies. Protecting this production system is thus important for the protection and inheritance of Chinese culture and traditional technologies. More than half of the jasmine tea in China is produced in Fuzhou Province (Xu et al., 2001; Yang et al., 2008; Xu, 2012). The system for culturing jasmine and other tea plants near the city of Fuzhou was added in 2014 to the United Nation's Globally Important Agricultural Heritage Systems due to its long historic, ecological, and cultural function in this region (Lin et al., 2014; Wang et al., 2014; Ren et al., 2015). The climate is very favorable for this activity, and the method for scenting the tea was developed here more than $1000 \mathrm{yr}$ ago (Qian, 2011; Xu, 2012).

Substituting common agricultural methods based on the intensive use of industrial fertilizers and the chemical control of crop pests by less environmentally aggressive methods is a challenge for the future viability of the extensive cultivation of crops such as jasmine and common teas. This is especially relevant in China, where the pollution associated with the rapid development has had severe environmental impacts. Organic agriculture does not use genetically engineered organisms, synthetic pesticides, industrial fertilizers, growth regulators, feed additives or other substances to maintain sustainable and stable agricultural production systems (AQSIQ, 2014).

\footnotetext{
W. Wang, Institute of Geography, Fujian Normal University, Fuzhou 350007, China and Key Laboratory of Humid Subtropical Eco-geographical Process, Ministry of Education, Fujian Normal University, Fuzhou 350007, China; Q. Min, Institute of Geographical Sciences and Natural Resources Research, Chinese Academy of Sciences, Beijing 100101, China; J. Sardans, CSIC, Global Ecology CREAF-CSIC-UAB, Cerdanyola del Valles, 08193 Barcelona, Catalonia, Spain and CREAF, Cerdanyola del Valles, 08193 Barcelona, Catalonia, Spain; C. Wang, Institute of Geography, Fujian Normal University, Fuzhou 350007, China and Key Laboratory of Humid Subtropical Eco-geographical Process, Ministry of Education, Fujian Normal University, Fuzhou 350007, China; D. Asensio, CSIC, Global Ecology CREAF-CSIC-UAB, Cerdanyola del Valles, 08193 Barcelona, Catalonia, Spain and CREAF, Cerdanyola del Valles, 08193 Barcelona, Catalonia, Spain; M. Bartrons, CSIC, Global Ecology CREAF-CSICUAB, Cerdanyola del Valles, 08193 Barcelona, Catalonia, Spain and CREAF, Cerdanyola del Valles, 08193 Barcelona, Catalonia, Spain; J. Peñuelas, CSIC, Global Ecology CREAF-CSIC-UAB, Cerdanyola del Valles, 08193 Barcelona, Catalonia, Spain and CREAF, Cerdanyola del Valles, 08193 Barcelona, Catalonia, Spain. ${ }^{*}$ Corresponding author (wangweiqi15@163.com; j.sardans@creaf.uab.cat).
} 
Organic cultivation in China is currently the most important method for simultaneously improving production quality and soil fertility (Deng et al., 2010). The impacts and consequences of the application of mid-term organic cultivation on $\mathrm{C}$ and nutrient allocation and stoichiometry in the plant-soil system, however, are poorly known. This information would provide the tools for introducing new management strategies (such as the controlled use of chemical fertilizers) to achieve long-term optimal nutrient conditions for the system as a whole, including an equilibrium among soil quality, crop yield and quality, and the pollution/eutrophication risk from the leaching of excess exchangeable soil nutrients.

The present study was conducted in subtropical jasmine and tea fields in Fujian Province, China. We chose fields that had long been cultivated using common and organic methods to ensure that any soil differences were due at least partially to the long-term differences between the two cultivation types. Plantations for the production of organic and common jasmine and tea have different basic strategies of crop management (Supplemental Table S1). We then (i) studied the soil pH, texture of soils in the two cultivation types (ii) studied the nutrient concentrations, contents, and stoichiometric ratios of the plants and soils in the two cultivation types, (iii) examined the relationship between cultivation type and the soil-plant capacity to store $\mathrm{C}$ and of $\mathrm{CO}_{2}$ emissions, and (iv) the overall shifts in plant-soil stoichiometry and soil texture among the two crop species under different cultivation type.

\section{MATERIALS AND METHODS}

\section{Study Area}

This study was conducted in the jasmine and tea culture system near the city of Fuzhou, which is one of the globally important agricultural heritage systems (Supplemental Fig. S1). The system includes Jin'an and Cangshan districts and Minhou, Lianjiang, and Yongtai counties, Changle County in Fuzhou City, Fujian Province, P.R. China, at $118^{\circ} 08^{\prime}-120^{\circ} 31^{\prime} \mathrm{E}$ and $25^{\circ} 15^{\prime}-26^{\circ} 29^{\prime} \mathrm{N}$. The climate is subtropical with mean annual temperatures and precipitation of $19.7^{\circ} \mathrm{C}$ and $1349 \mathrm{~mm}$, respectively. The frost-free period is $>300 \mathrm{~d}$. The soil type is red soil. The system is in a hilly area of agroforestry eco-systems in southeastern China. Mountainous and hilly areas cover $72.7 \%$ of the region with complex topography. Green tea and jasmine cultivation provide $30 \%$ of total household income, and migrant labor and trade provide the remainder. As stated above, the jasmine in Fuzhou is mostly planted in riverside wetlands and shoals (Supplemental Fig. S2). From high to low elevation, one can see, in the following order, tea plants, trees, buildings, jasmine plants, and waterways. Cultivated jasmine and tea trees can enhance water and soil conservation in many ways (Wang et al., 2014). Jasmine trees are mostly planted on the plains and shoals along rivers. They thus prevent rainwater from directly scouring the riverside, thereby mitigating soil and water erosion. Tea trees are planted in terraced fields. The trees enhance the infiltration of water into the soil and decrease the amount and speed of surface-water runoff and thus the scouring of the soils on the slopes, thereby contributing greatly to soil and water conservation (Wang et al., 2014). Jasmine and tea cultivation also improve air quality and increase $\mathrm{C}$ fixation, oxygen release, and nutrient storage (Ren et al., 2014; Wang et al., 2014). Jasmine and tea trees, together with their diversified microclimates, have contributed to the topographic complexity of these regions of China.

\section{Experimental Design}

We established 12 plots on a jasmine and a tea plantation to determine the associations between organic cultivation and the concentrations and ratios of plant and soil C, N, P, and K. Three plots $\left(1 \mathrm{~m}^{2}\right.$ each) were randomly selected at each of the organic jasmine, common jasmine, organic tea, and common tea sampling locations at the two sites (two types of plantation $\times$ two types of cultivation $=$ four stands). We collected aboveground biomass from stands of the organic and common cultivation plots at the jasmine and tea plantations. We randomly sampled the aboveground biomass from three randomly selected subquadrats ( 1 by $1 \mathrm{~m}$ ) in each stand. Soil and plant samples were collected in March 2013, which was within the growth period.

\section{Collection and Analysis of Soil and Plant Samples}

One soil profile (width, $1 \mathrm{~m}$; length, $1 \mathrm{~m}$; depth, $0.5 \mathrm{~m}$ ) was excavated in each plot. Samples were collected with a small sampler (length, $0.3 \mathrm{~m}$; diameter $0.1 \mathrm{~m}$ ) from each of five soil layers $(0-10,10-20,20-30,30-40$, and $40-50 \mathrm{~cm})$ at the center and on both sides of the soil pits. These three samples from each layer were bulked to form one sample per layer. A total of 60 soil samples (two types of plantation $\times$ two types of cultivation $\times$ three plots $\times$ five layers) were thus collected.

In the laboratory, the samples were air-dried, roots and visible plant remains were removed, and the samples were finely ground in a ball mill. The soil $\mathrm{C}$ and $\mathrm{N}$ concentrations were determined using a Vario MAX CN Elemental Analyzer (Elementar Scientific Instruments, Hanau, Germany). Total soil $\mathrm{P}$ concentration was determined by perchloric-acid digestion followed by ammonium-molybdate colorimetry and measurement using a UV-2450 spectrophotometer (Shimadzu Scientific Instruments, Kyoto, Japan) and total K concentration was determined by FP 640 flame photometry (Shanghai Electronic Technology Instruments, Shanghai, China).

Soil bulk density was measured from three 5 by $3 \mathrm{~cm}$ cores per layer, salinity was measured with a DDS-307 conductivity meter (Boqu Scientific Instruments, Shanghai, China), pH was measured with an 868 pH meter (Orion Scientific Instruments, Waltham, MA), particle size (clay, silt, and sand) was measured by a Mastersizer 2000 laser particle-size analyzer (Malvern Scientific Instruments, Suffolk, UK), water content was measured by the drying method (Lu, 1999) and $\mathrm{C}\left(\mathrm{CO}_{2}\right)$ release was determined by the incubation method (Wang et al., 2010). Briefly, $30 \mathrm{~g}$ of fresh soil were placed into $120-\mathrm{mL}$ incubation bottles. The bottles were sealed with rubber stoppers and incubated at $20^{\circ} \mathrm{C}$ for $3 \mathrm{~d}$. Five milliliters of gas were extracted from the headspaces four times a day. Carbon dioxide concentration was determined by GC-2014 gas chromatography (Shimadzu Scientific Instruments, Kyoto, Japan).

Aboveground plant samples were collected from a consistent height to reduce the potential effects of site-specific confounding variables. The biomass was sorted into leaves and branches. Belowground biomass was collected from the sample subquadrats. All plant material was gently washed with water and then ovendried to a constant weight $\left(80^{\circ} \mathrm{C}\right.$ for $\left.24-36 \mathrm{~h}\right)$ and weighed. A 
Jasmine C concentration $\left(\mathrm{g} \mathrm{kg}^{-1}\right)$
Tea

C concentration $\left(\mathrm{g} \mathrm{kg}^{-1}\right)$
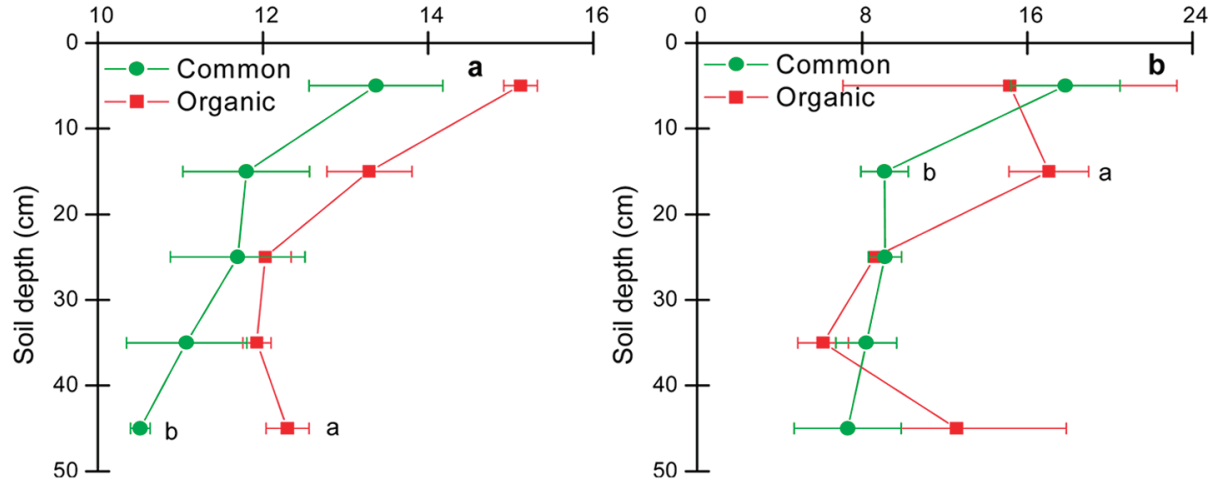

$\mathrm{N}$ concentration $\left(\mathrm{g} \mathrm{kg}^{-1}\right)$

$\mathrm{N}$ concentration $\left(\mathrm{g} \mathrm{kg}^{-1}\right)$
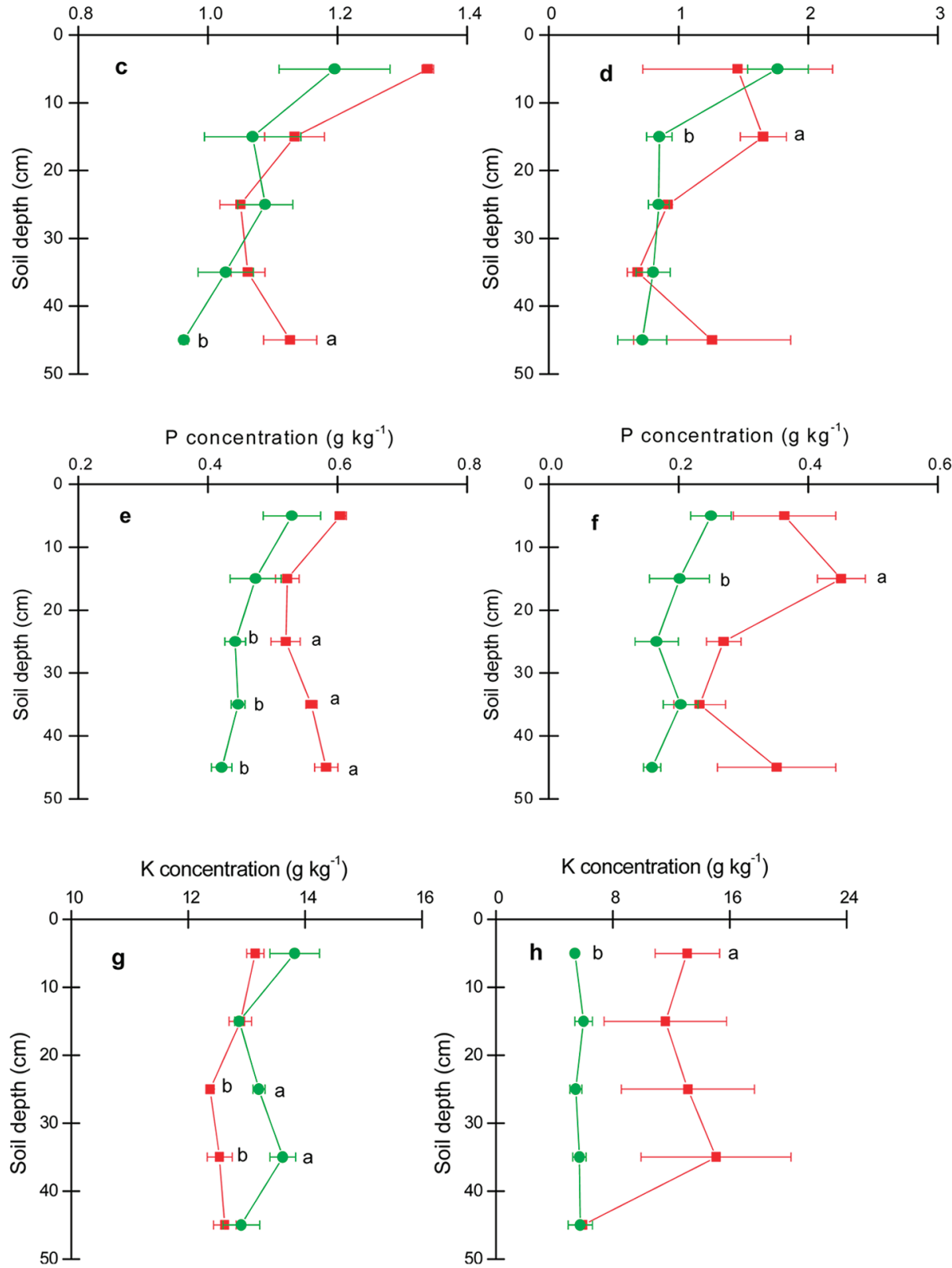

Fig. I. Concentrations (mean \pm SE) of soil $(a, b) C,(c, d) N,(e, f) P$, and $(g, h) K$ in the jasmine and tea plantations. Different letters indicate significant differences $(P<0.05)$ between organic and common cultivation in a paired-samples $t$ test. Error bar indicates standard error of the mean of triplicate measurements. (Green color indicates data corresponding to common cultivation method, whereas red color indicates data corresponding to organic cultivation method). 

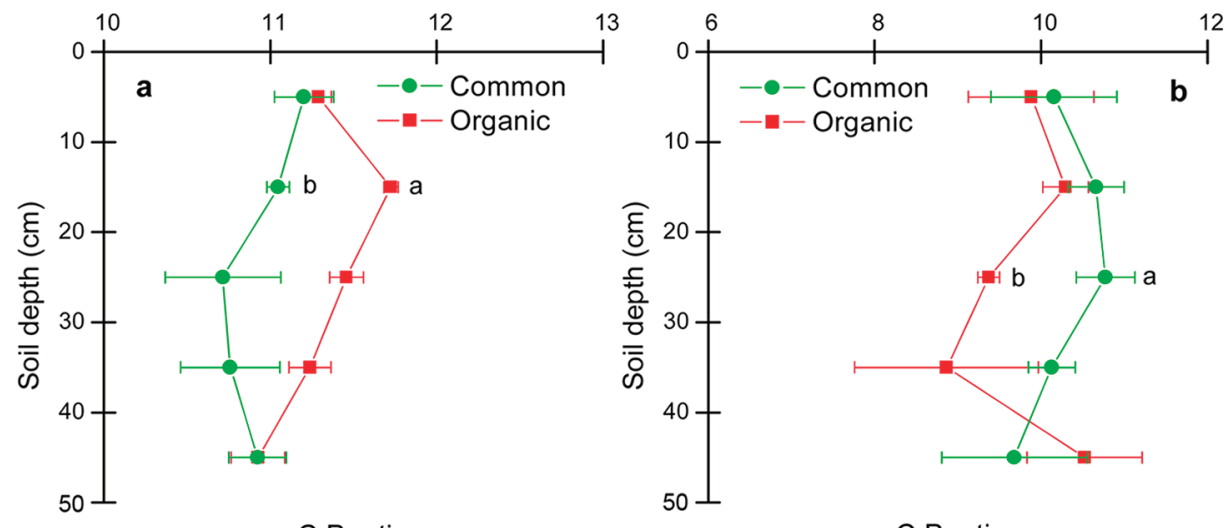

C:P ratio

C:P ratio

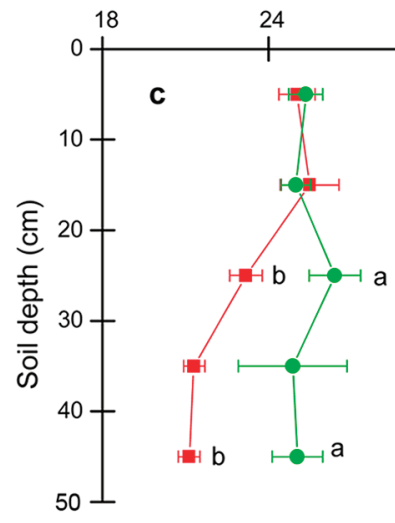

C:K ratio
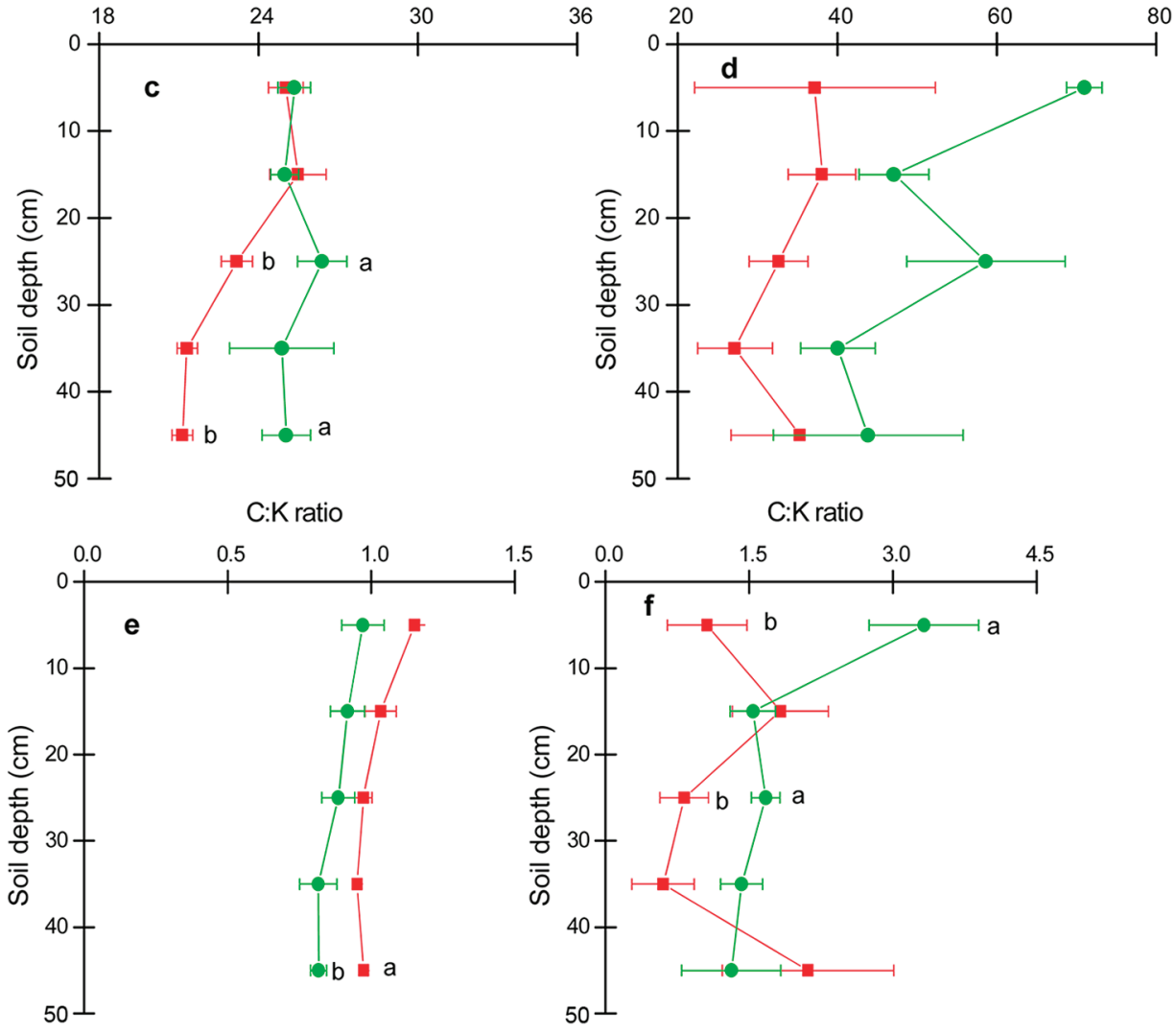

$\mathrm{N}: \mathrm{P}$ ratio
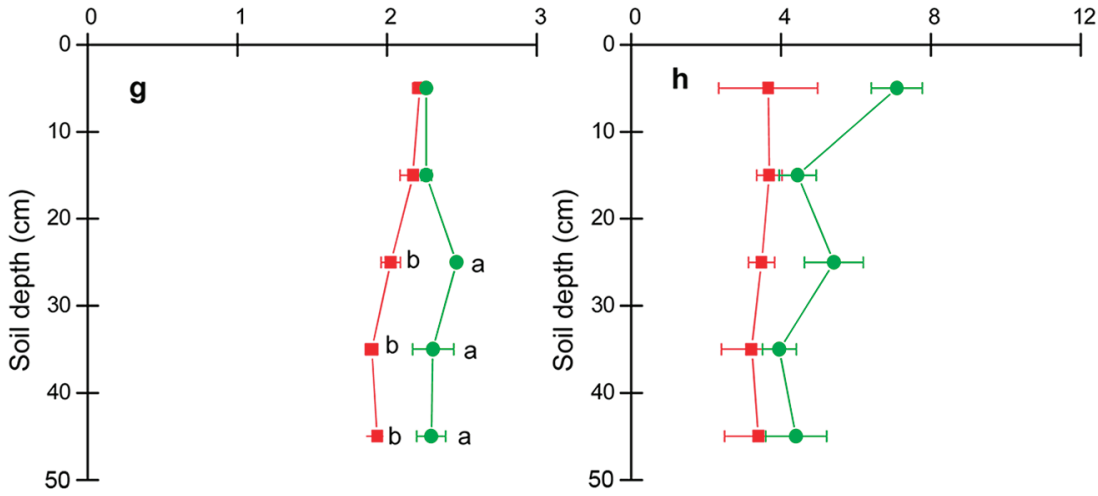

Fig. 2. (a, b) Soil C/N, (c, d) C/P, (e, f) C/K, and (g, h) N/P ratios (mean $\pm \mathrm{SE}$ ) in the jasmine and tea plantations. Different letters indicate significant differences $(P<0.05)$ between organic and common cultivation in a paired-samples $t$ test. Error bar indicates standard error of the mean of triplicate measurements. (Green color indicates data corresponding to common cultivation method, whereas red color indicates data corresponding to organic cultivation method). (Figure 2 is continued on the next page.) 
total of 36 plant samples (two types of plantation $\times$ two types of cultivation $\times$ three plots $\times$ three organs) were thus collected.

The plant $\mathrm{C}$ and $\mathrm{N}$ concentrations were determined using a Vario EL III Elemental Analyzer (Elementar Scientific Instruments, Hanau, Germany). The P concentrations of the plants were measured using the molybdate-blue reaction (Lu, 1999) with a UV-2450 spectrophotometer (Shimadzu Scientific Instruments, Kyoto, Japan). Potassium concentration was determined by FP 640 flame photometry (Shanghai Electronic Technology Instruments, Shanghai, China).

\section{Carbon, Nitrogen, Phosphorus, and Potassium Content and Release}

Carbon, N, P, and $\mathrm{K}$ content for the 0 - to 50 - $\mathrm{cm}$ profiles were estimated using the equation (Mishra et al., 2010):

$$
C_{s}=\sum_{j=1}^{n} \times \rho_{\mathrm{b}} \times D
$$

where $C_{S}$ is $\mathrm{C}, \mathrm{N}, \mathrm{P}$, or $\mathrm{K}$ content $\left(\mathrm{kg} \mathrm{m}^{-2}\right)$; $\mathrm{j}$ is the soil-depth interval $(1,2, \ldots \mathrm{n}) ; C_{m}$ is the $\mathrm{C}, \mathrm{N}, \mathrm{P}$, or $\mathrm{K}$ concentration $\left(\mathrm{g} \mathrm{kg}^{-1}\right) ; \rho_{\mathrm{b}}$ is the bulk density $\left(\mathrm{kg} \mathrm{m}^{-3}\right) ; D$ is the thickness of each layer ( $\mathrm{m})$ and $n$ is the number of layers.
Carbon release was estimated using the equation (Wassmann et al., 1998):

$$
P=\frac{d c}{d t} \times \frac{V_{H}}{W_{S}} \times \frac{\mathrm{MW}}{\mathrm{MV}} \times \frac{T_{s t}}{T_{s t}+T}
$$

where $P$ is the rate of $C$ release $\left(\mathrm{mg}^{-1} \mathrm{~kg}^{-1} \mathrm{~d}^{-1}\right), \mathrm{dc} / \mathrm{dt}$ is the recorded change in the mixing ratio of $\mathrm{C}\left(\mathrm{CO}_{2}\right)$ in the headspace over time $\left(\mathrm{mmol} \mathrm{mol}^{-1} \mathrm{~d}^{-1}\right), V_{H}$ is the volume of the headspace $(\mathrm{L}), W_{s}$ is the dry weight of the soil $(\mathrm{g}), \mathrm{MW}$ is the molecular weight of $\mathrm{CO}_{2}(\mathrm{~g}), \mathrm{MV}$ is the molecular volume $(\mathrm{L}), T$ is the air temperature $(\mathrm{K})$, and $T_{s \mathrm{t}}$ is the standard temperature $(\mathrm{K})$. Most $\mathrm{C}$ release from the wetland soil in the study area was in the form of $\mathrm{CO}_{2}$ (Wang et al., 2010). We also expected that the main form of $\mathrm{C}$ release would not be $\mathrm{CH}_{4}$, because some of the land uses were not wetlands and thus had no anaerobic periods, so we only determined $\mathrm{CO}_{2}$ release.

\section{Statistical Analyses}

We used general linear models (GLM) with plantation type (tea and jasmine), cultivation type (common and organic) and soil depth as independent categorical variables and with the soil and plant variables as dependent continuous variables. We also used paired-samples $t$ tests to compare the variables between
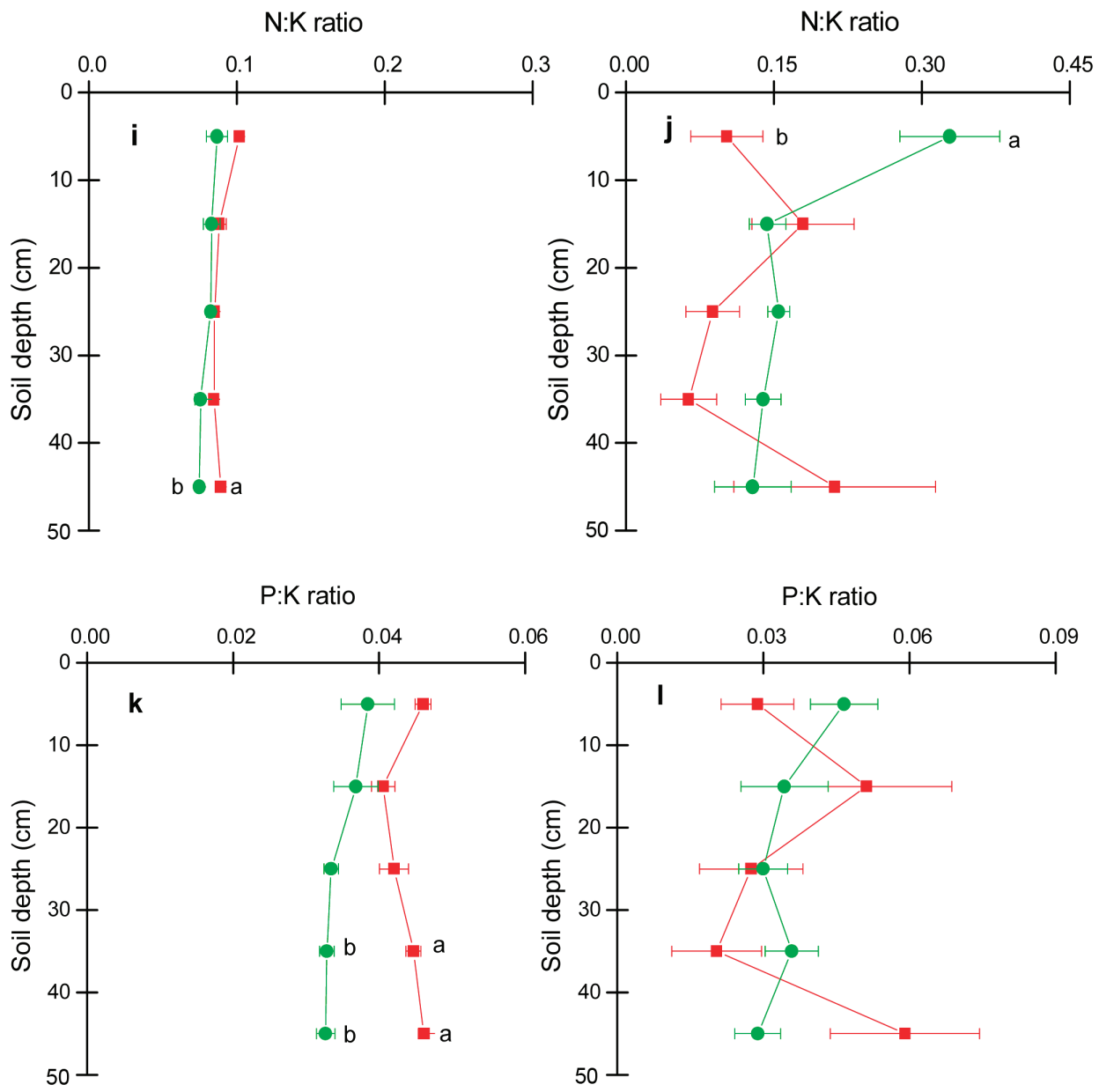

Fig. 2. continued. (i, j) Soil N/K and ( $k$, l) P/K ratios (mean $\pm \mathrm{SE}$ ) in the jasmine and tea plantations. Different letters indicate significant differences $(P<0.05)$ between organic and common cultivation in a paired-samples $t$ test. Error bar indicates standard error of the mean of triplicate measurements. (Green color indicates data corresponding to common cultivation method, whereas red color indicates data corresponding to organic cultivation method). 
common vs. organic cultivation within each plantation type. We used Statistica 8.0 (StatSoft, Inc., Tulsa, OK) for the analyses. The relationships among the soil variables were examined by Pearson correlation analysis.

We also performed multivariate statistical analyses using a general discriminant analysis (GDA) to determine the overall differences in soil traits in the tea and jasmine plantations with common and organic cultivation. We also took into account the component of the variance due to the different soil depths as an independent categorical variable. Discriminant analyses consist of a supervised statistical algorithm that derives an optimal separation between groups established a priori by maximizing between-group variance while minimizing withingroup variance (Raamsdonk et al., 2001). The GDA is thus an adequate tool for identifying the variables most responsible for the differences among groups while controlling the component of the variance due to other categorical variables. The GDAs were performed using Statistica 6.0 (StatSoft, Inc., Tulsa, OK).

\section{RESULTS Univariate Analyses}

\section{Soil $\mathrm{pH}$ and Texture}

Organic cultivation was associated with higher soil $\mathrm{pH}$ for both the jasmine $(0-20 \mathrm{~cm})$ and tea $(0-50 \mathrm{~cm})$ plantations (Supplemental Fig. S3). Soil pH in the jasmine plantations was higher under organic than common cultivation. Soil texture was less sandy and contained higher proportions of clay under organic cultivation ( $>30 \mathrm{~cm}$, Supplemental Fig. S3). This difference was larger in the tea than the jasmine plantations, consistent with the longer time of organic tea $(30 \mathrm{yr})$ than jasmine $(5 \mathrm{yr})$ cultivation.

\section{Soils and Plant Nutrient and Carbon Concentration, Content, and Stoichiometry}

The organic cultivation of jasmine had higher soil $\mathrm{C}$ and $\mathrm{P}$ concentrations at 0 to $50 \mathrm{~cm}$, higher soil $\mathrm{N}$ concentrations at 10 to 20 and 40 to $50 \mathrm{~cm}$ and lower $\mathrm{K}$ concentrations at 20 to 50 $\mathrm{cm}$ than common cultivation. The organic cultivation of tea had higher soil C concentrations at 10 to 20 and 40 to $50 \mathrm{~cm}$, higher $\mathrm{N}$ concentrations at 10 to 30 and 40 to $50 \mathrm{~cm}$ and higher $\mathrm{P}$ and $\mathrm{K}$ concentrations at 0 to $50 \mathrm{~cm}$ than common cultivation (Fig. 1). The soils under organic cultivation at all depths had higher $\mathrm{P}(F=$ 39.7, $P<0.00001)$ and $\mathrm{K}(F=11.1, P=0.0015)$ concentrations relative to the soils under common cultivation. The soils in the jasmine plantations had higher $\mathrm{P}(F=176, P<0.00001)$ and $\mathrm{K}(F=26.7, P<0.0001)$ concentrations than those in the tea plantations regardless of the cultivation type (Fig. 1).

These differences in soil elemental concentrations associated with the cultivation type were greater than the differences in soil stoichiometry. Soil C/N, C/K, N/K, and $\mathrm{P} / \mathrm{K}$ ratios were higher and soil $\mathrm{C} / \mathrm{P}$ and $\mathrm{N} / \mathrm{P}$ ratios lower at most depths under organic than common cultivation in the jasmine plantations (Fig. 2). Soil $\mathrm{C} / \mathrm{N}$ and $\mathrm{C} / \mathrm{K}$ ratios at most depths were lower under organic than common cultivation in the tea plantations (Fig. 2). The GLM indicated that the $\mathrm{C} / \mathrm{P}, \mathrm{C} / \mathrm{K}, \mathrm{N} / \mathrm{P}$, and $\mathrm{N} / \mathrm{K}$ ratios were lower in the jasmine than the tea soil profiles (Supplemental Table S2).

Organic cultivation had higher soil $\mathrm{P}$ contents $\left(\mathrm{Mg} \mathrm{ha}^{-1}\right)$ at $>30 \mathrm{~cm}$ in the jasmine plantations and with higher $\mathrm{C}, \mathrm{N}$, and $\mathrm{P}$ contents at 10 to $20 \mathrm{~cm}$ in the tea plantations (Fig. 3). Carbon and $\mathrm{N}$ contents were lower and $\mathrm{P}$ and $\mathrm{K}$ contents were higher throughout the soil profiles in the jasmine than the tea plantations (Supplemental Table S2). Soil P concentration was strongly and positively correlated $(R=0.69, P<0.0001)$ with clay concentration (Supplemental Table S3), showing that the higher clay concentration with organic cultivation was associated with the higher P concentrations.

Organic cultivation was associated with lower $\mathrm{N}, \mathrm{P}$, and $\mathrm{K}$ concentrations in the leaves, stems, and roots and with lower $\mathrm{C}$ concentrations in the leaves and higher $\mathrm{C}$ concentrations in the roots of jasmine trees relative to common cultivation (Fig. 4). Organic tea cultivation had lower foliar and root $\mathrm{C}$ and $\mathrm{N}$ concentrations, and stem $\mathrm{N}$ concentrations and higher foliar $\mathrm{P}$ and $\mathrm{K}$ concentrations, stem $\mathrm{C}, \mathrm{N}$, and $\mathrm{P}$ concentrations, and root $\mathrm{P}$ concentrations (Fig. 4). Foliar C/N, C/P, C/K, $\mathrm{N} / \mathrm{K}$, and $\mathrm{P} / \mathrm{K}$ ratios were higher and $\mathrm{N} / \mathrm{P}$ ratios were lower in jasmine trees under organic than common cultivation (Fig. 5). Stem $\mathrm{C} / \mathrm{N}, \mathrm{C} / \mathrm{P}, \mathrm{C} / \mathrm{K}, \mathrm{N} / \mathrm{P}, \mathrm{N} / \mathrm{K}$, and $\mathrm{P} / \mathrm{K}$ ratios and root $\mathrm{C} / \mathrm{N}, \mathrm{C} / \mathrm{P}$, and $\mathrm{C} / \mathrm{K}$ ratios were higher and $\operatorname{root} \mathrm{N} / \mathrm{P}, \mathrm{N} / \mathrm{K}$, and $\mathrm{P} / \mathrm{K}$ ratios were lower in jasmine trees under organic cultivation (Fig. 5).

The $\mathrm{C} / \mathrm{P}, \mathrm{N} / \mathrm{K}$, and $\mathrm{N} / \mathrm{P}$ ratios were lower and $\mathrm{C} / \mathrm{N}$ and $\mathrm{P} / \mathrm{K}$ ratios were higher in the leaves, stems, and roots of the tea trees under organic than common cultivation (Fig. 5). Foliar and stem $\mathrm{C} / \mathrm{K}$ ratios were lower in the tea trees under organic than common cultivation (Fig. 5).

None of the interactions between plantation type and cultivation type for biomasses and mineralomasses were significant (Supplemental Table S4). Root biomasses were higher in the jasmine than the tea plantations. Potassium contents were higher in all organs, $\mathrm{N}$ contents were higher in stems and roots, and $\mathrm{C}$ and $\mathrm{P}$ contents were higher in roots in the jasmine than the tea plantations (Supplemental Table S4). Plants under organic cultivation had lower P contents in all organs and lower K contents in leaves and stems (Supplemental Table S4). Carbon, $\mathrm{N}$, and $\mathrm{K}$ mineralomasses were higher in the jasmine than the tea plantations. Total P mineralomasses were lower under organic cultivation (Supplemental Table S5). The total mineralomass $\mathrm{C} / \mathrm{N}, \mathrm{C} / \mathrm{P}, \mathrm{N} / \mathrm{P}, \mathrm{C} / \mathrm{K}$, and $\mathrm{P} / \mathrm{K}$ ratios were higher in the tea than the jasmine plantations, whereas the total mineralomass $\mathrm{C} / \mathrm{N}, \mathrm{C} / \mathrm{P}, \mathrm{N} / \mathrm{P}, \mathrm{C} / \mathrm{K}$, and $\mathrm{N} / \mathrm{K}$ ratios were higher and $\mathrm{P} / \mathrm{K}$ ratios were lower under organic than common cultivation (Supplemental Table S5).

\section{Soil Carbon Dioxide Emission}

Soil $\mathrm{CO}_{2}$ emissions were higher with organic cultivation from 0 to $10 \mathrm{~cm}$ in the jasmine plantations and at depths $>20 \mathrm{~cm}$ in the tea plantations (Fig. 6). Carbon dioxide emissions throughout the soil profile were higher in the tea plantations under common cultivation (Supplemental Table S2).

\section{Multivariate Analysis. Overall Differences among Crop Types and Cultivation Methods}

The GDA showed that the soil variables separated all four combinations of plantation $\times$ cultivation type (jasmine with common cultivation, jasmine with organic cultivation, tea with common cultivation, and tea with organic cultivation) (Supplemental Table S6, Fig. 7). Soil total C, N, and P concentrations, $\mathrm{N} / \mathrm{K}$ and $\mathrm{P} / \mathrm{K}$ ratios, and $\mathrm{C}$ and $\mathrm{N}$ contents had significant loadings in the model (Supplemental Table S7). 
Jasmine

Tea

C content $\left(\mathrm{Mg} \mathrm{ha}^{-1}\right)$

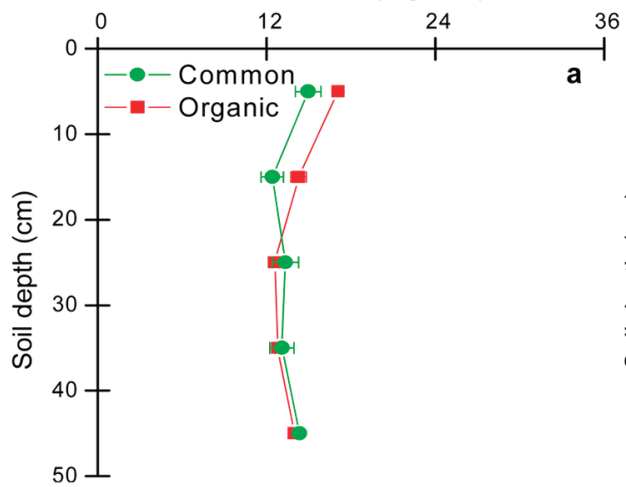

C content $\left(\mathrm{Mg} \mathrm{ha}^{-1}\right)$

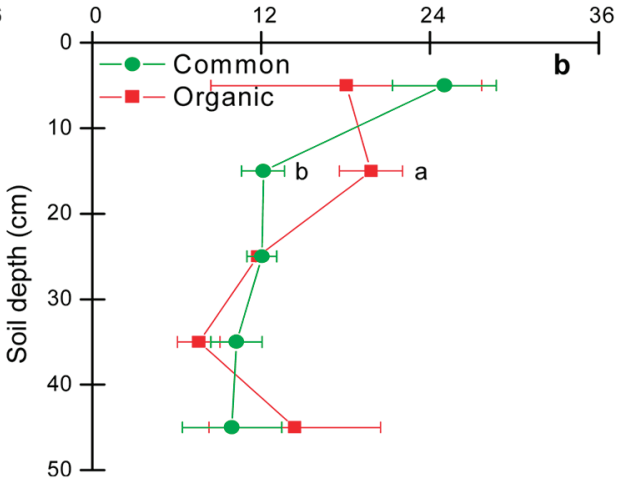

$\mathrm{N}$ content $\left(\mathrm{Mg} \mathrm{ha}^{-1}\right)$

$\mathrm{N}$ content $\left(\mathrm{Mg} \mathrm{ha}^{-1}\right)$
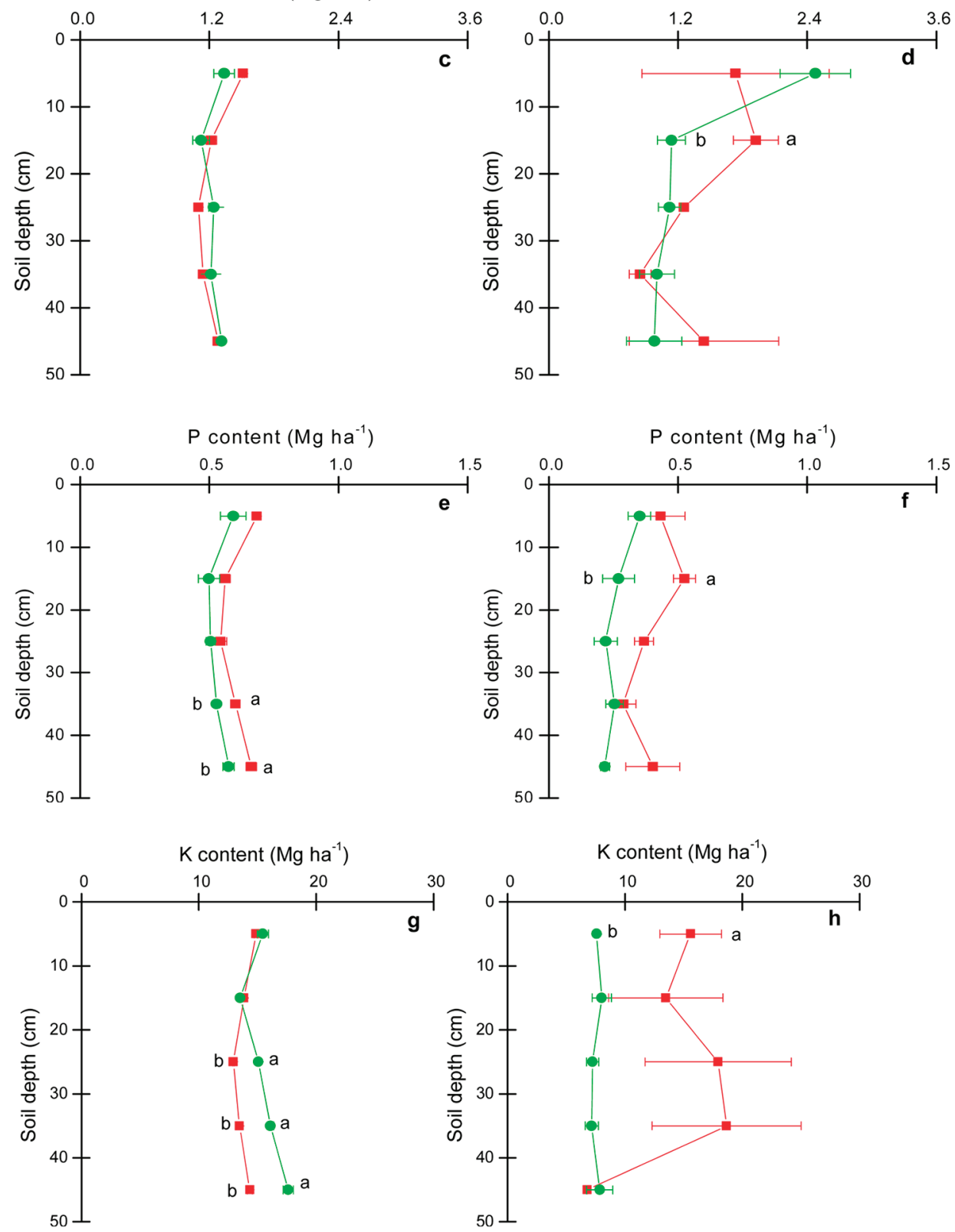

Fig. 3. (a, b) Soil C, (c, d) N, (e, f) P, and (g, h) K contents (mean \pm SE) in the jasmine and tea plantations. Different letters indicate significant differences $(P<0.05)$ between organic and common cultivation in a paired-samples $t$ test. Error bar indicates standard error of the mean of triplicate measurements. (Green color indicates data corresponding to common cultivation method, whereas red color indicates data corresponding to organic cultivation method). 

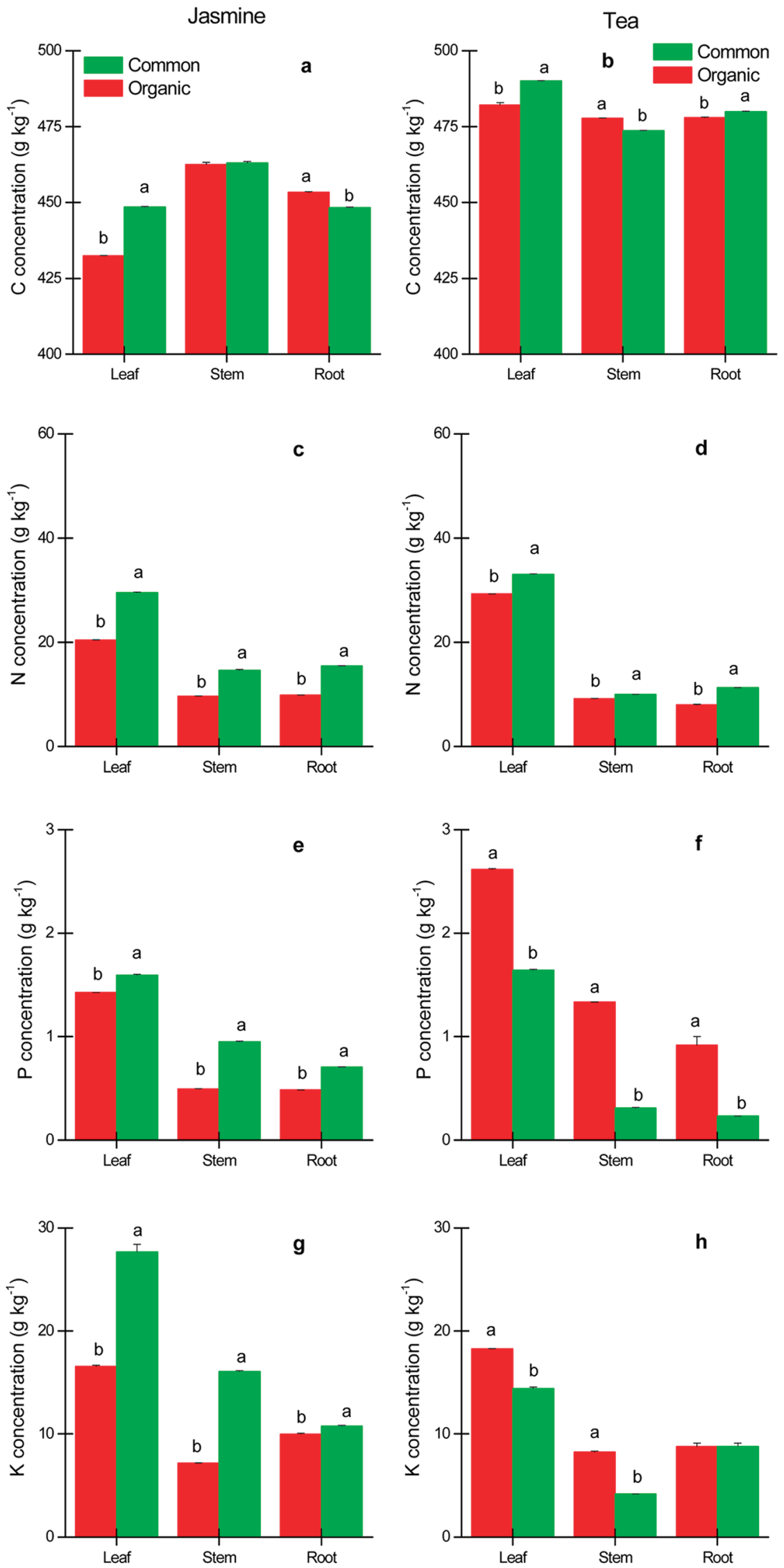

Fig. 4. (a, b) Plant C, (c, d) N, (e, f) P, and (g, h) K concentrations (mean \pm SE) in the jasmine and tea plantations. Different letters indicate significant differences $(P<0.05)$ between organic and common cultivation in a paired-samples $t$ test. Error bar indicates standard error of the mean of triplicate measurements. (Green color indicates data corresponding to common cultivation method, whereas red color indicates data corresponding to organic cultivation method). 
Jasmine
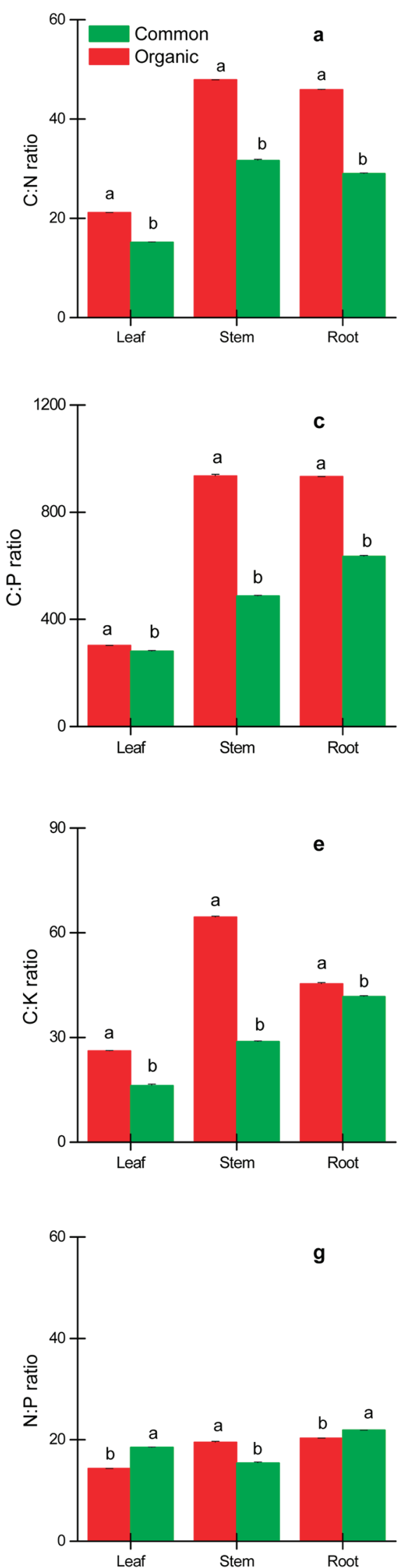

Tea
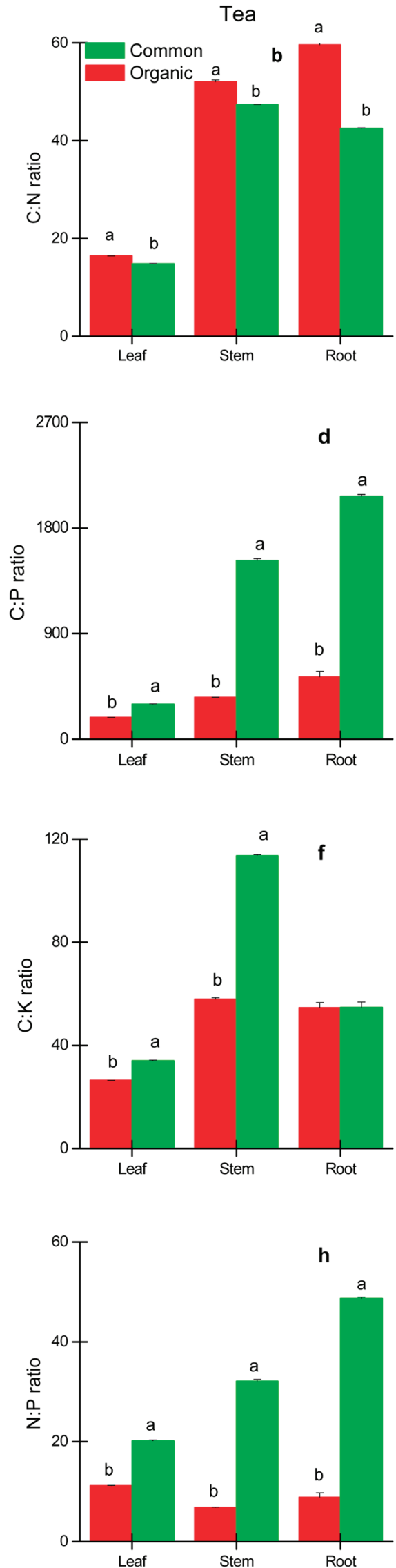

Fig. 5. (a, b) Plant C/N, (c, d) C/P, (e, f) C/K, and (g, h) N/P ratios (mean $\pm \mathrm{SE}$ ) in the jasmine and tea plantations. Different letters indicate significant differences $(P<0.05)$ between organic and common cultivation in a paired-samples $t$ test. Error bar indicates standard error of the mean of triplicate measurements. (Green color indicates data corresponding to common cultivation method, whereas red color indicates data corresponding to organic cultivation method). (Figure 5 is continued on the next page.) 


\section{DISCUSSION}

\section{Soil Texture}

Organic cultivation was correlated with the higher proportion of clay than sand in these soils. This effect was greater in the tea than the jasmine plantations, also consistent with the longer period of organic cultivation in the tea plantations. These results thus strongly suggest that organic cultivation contributed to the enrichment of clay in the soils, thereby
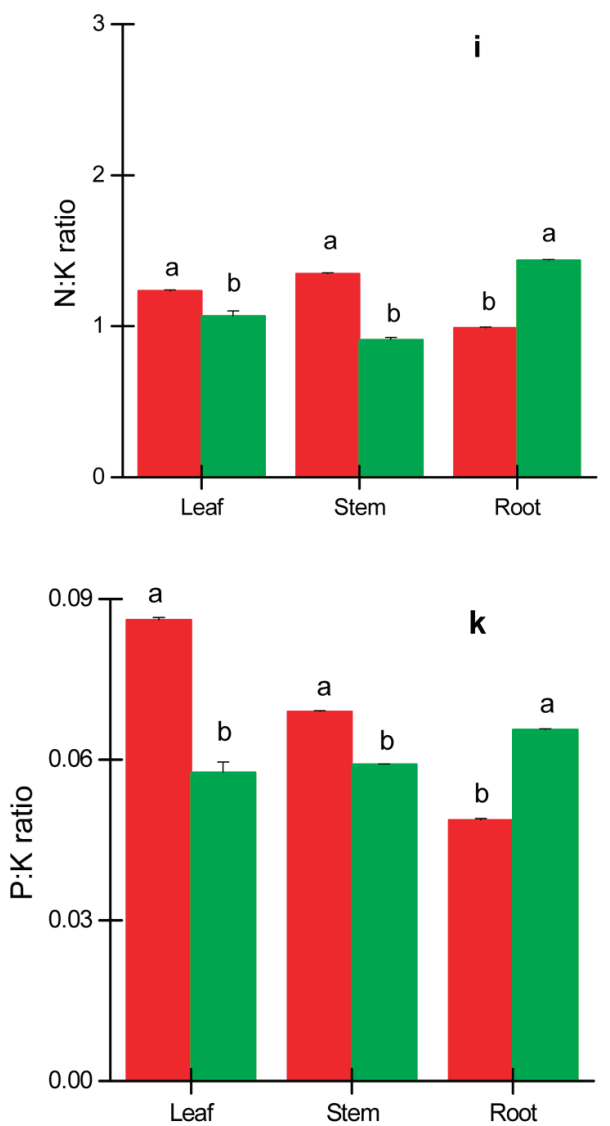

changing the soil texture and contributing to the capacity of the soil to store/release nutrients. Moreover, the higher soil $\mathrm{P}$ concentrations and lower soil N/P ratios in the soils under organic cultivation in tea crops were correlated with the higher proportion of clay than sand in these soils. Thus, the results strongly suggested that the observed changes in soil elemental composition associated to organic cultivation should be due at least in part to the related increase of soil clay concentration.
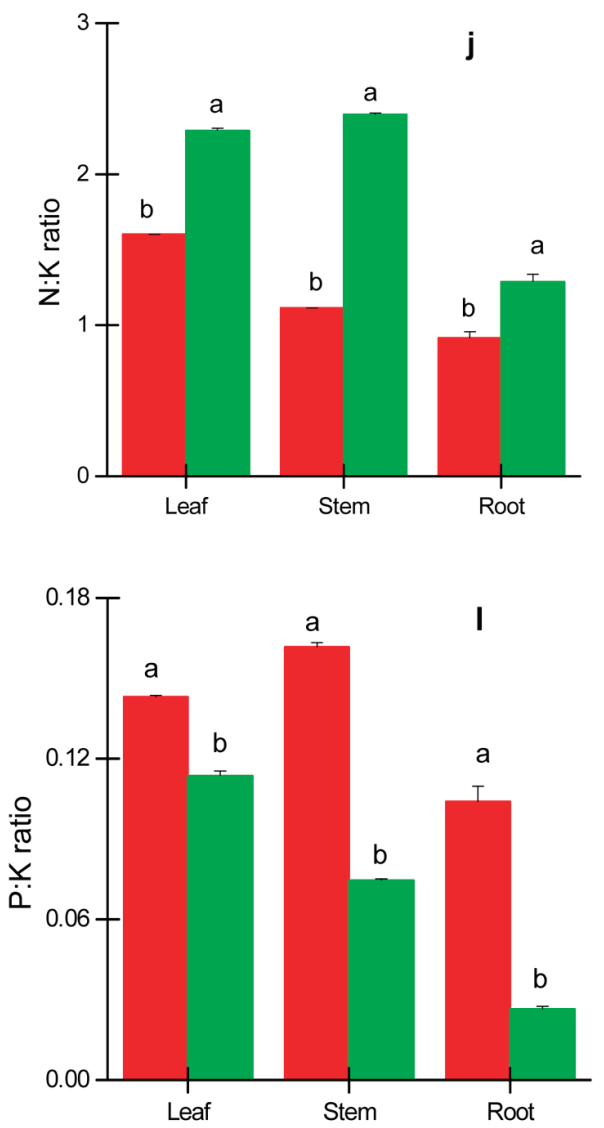

Fig. 5. continued. (i, j) Plant N/K and ( $k$, l) P/K ratios (mean \pm SE) in the jasmine and tea plantations. Different letters indicate significant differences $(P<0.05)$ between organic and common cultivation in a paired-samples $t$ test. Error bar indicates standard error of the mean of triplicate measurements. (Green color indicates data corresponding to common cultivation method, whereas red color indicates data corresponding to organic cultivation method).
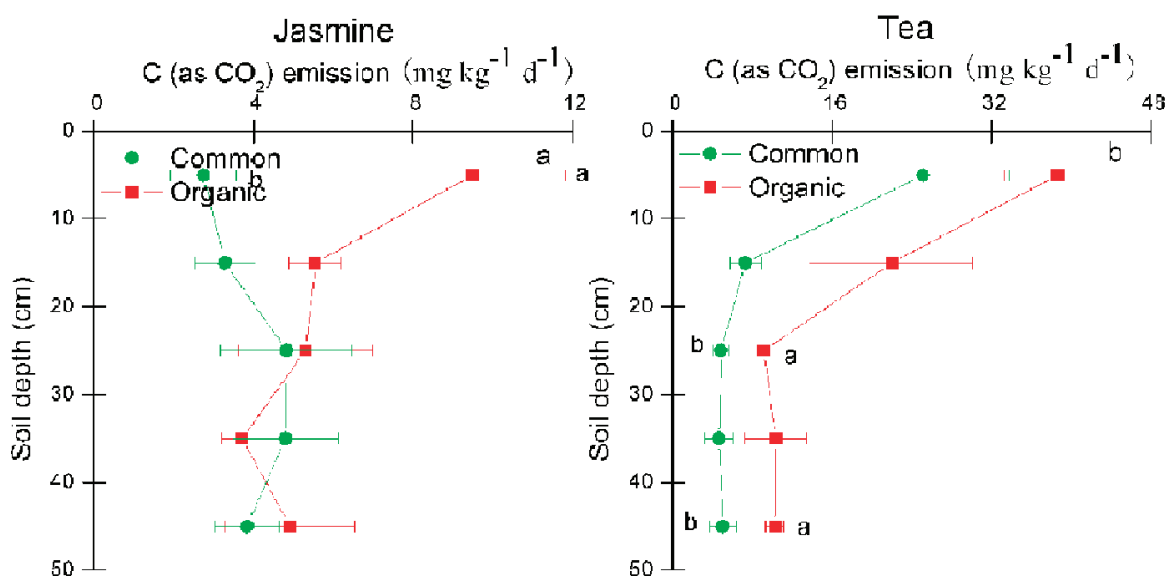

Fig. 6. Emissions (mean $\pm \mathrm{SE}$ ) of $(\mathrm{a}, \mathrm{b}) \mathrm{C}$ (as $\mathrm{CO}_{2}$ ) in soils from jasmine and tea cultivation. Different letters indicate significant differences $(P<0.05)$ between organic and common cultivation in a paired-samples $t$ test. Error bar indicates standard error of the mean of triplicate measurements. (Green color indicates data corresponding to common cultivation method, whereas red color indicates data corresponding to organic cultivation method). 


\section{Plant and Soil Nutrients Concentrations, Content, and Stoichiometry}

Organic cultivation was not associated with changes in plantation biomasses but was associated with changes in plant and soil nutrient concentrations and stoichiometric ratios. Organic cultivation had higher soil $\mathrm{N}$ and $\mathrm{P}$ concentrations and contents in both the jasmine and tea plantation at some soil depths. Under organic cultivation tea and jasmine plants had higher $\mathrm{C} / \mathrm{N}$, whereas tea had lower $\mathrm{C} / \mathrm{P}$ ratios and jasmine higher $\mathrm{C} / \mathrm{P}$ ratios in total biomass thus suggesting higher $\mathrm{N}$ and $\mathrm{P}$-use efficiency in jasmine and higher $\mathrm{N}$ - and lower P-use efficiency in tea. Soil elemental ratios differed between the two cultivation types. Phosphorus concentration was proportionally higher than $\mathrm{C}$ and $\mathrm{N}$ concentrations under organic cultivation in both plantation types, whereas $\mathrm{C} / \mathrm{N}$ and $\mathrm{P} / \mathrm{K}$ ratios differed between the two cultivation types, depending on the plantation type. Jasmine trees had higher allocations of biomass and nutrients to the roots, higher overall $\mathrm{C}, \mathrm{N}$, and $\mathrm{K}$ contents and lower $\mathrm{C} /$ nutrients and $\mathrm{N} / \mathrm{P}$ ratios than the tea trees.

In jasmine whereas $\mathrm{P}$ concentrations were higher in soil under organic cultivation, they were lower in biomass, further suggesting an increase of $\mathrm{P}$ use efficiency. Differently, $\mathrm{P}$ concentrations increased in both soil and biomass in tea cropland organic cultivation. These results provide evidences that the association of organic cultivation with plant-soil stoichiometry in croplands depends on cropland type. However, under organic cultivation we observed a decrease of soil total $\mathrm{K}$ concentrations in certain soil depths in jasmine croplands and an increase in tea croplands. The different effects of organic cultivation on soil texture between the two cultivation methods seems to be underlying these different responses between the two studied species. The higher clay concentrations observed in tea soils under organic cultivation are consistent with the increases in soil $\mathrm{K}$ contents, because $\mathrm{K}^{+}$is

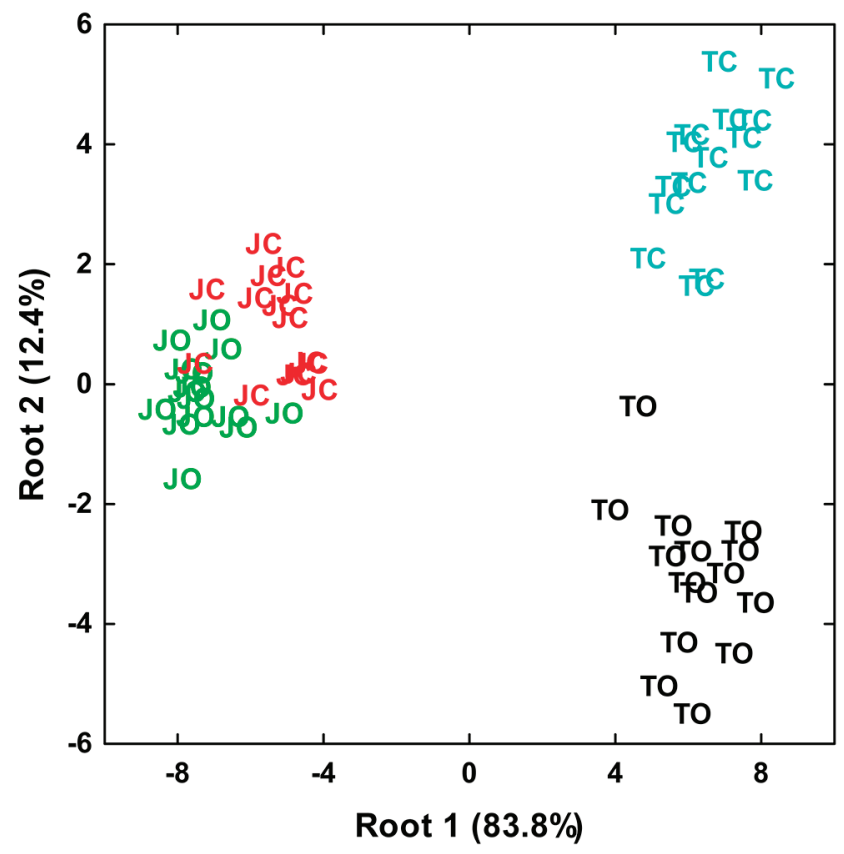

Fig. 7. Biplot of the standardized canonical discriminate function coefficients for the first two roots representing the various grouping dependent factors corresponding to the plant communities. JC, = jasmine common cultivation; $\mathrm{JO}=$ jasmine organic cultivation; $\mathrm{TC}$, = tea common cultivation; $\mathrm{TO}$, = tea organic cultivation. strongly retained by clay in soils (Cofie and Pleysier, 2004; Blank, 2010) and at the same time clay is a primary source of new $\mathrm{K}^{+}$ (Askegaard et al., 2003; Blank, 2010). The different potential leaching/sedimentary balance in the bottom of the valleys in the river flooding areas in the case of jasmine croplands with respect to the soils of the top of the mountain in the case of teas opens different scenarios and interactions with organic cultivation. In any case, both the soil total $\mathrm{N}$ and $\mathrm{P}$ concentrations increase under organic cultivation in both crops. Increases in $\mathrm{P}$ and other nutrients such as $\mathrm{Zn}$ and $\mathrm{Cu}$ in soil have been associated with the organic cultivation of cotton (Gossypium hirsutum L.) (Blaise et al., 2004). Organic cultivation has been widely demonstrated to be able to improve the chemical traits of plantation types and their nutritional quality, including higher vitamin concentrations and contents of total phenolics and soluble sugars (Del Amor et al., 2008; Hallmann, 2012; Lombardo et al., 2012). Organic cultivars have been associated with decreases in plant biomass $\mathrm{N}$ and $\mathrm{P}$ concentrations, also in agreement with our results (López et al., 2013). In contrast to our results, however, the organic cultivation of strawberries (Frageria vesca L.) did not induce changes in macronutrient concentrations between plant tissues (Hargreaves et al., 2008).

\section{Plant and Soil Carbon Concentrations, Content, and Stoichiometry}

The higher levels of $\mathrm{C}$ stored in the soil despite the higher $\mathrm{CO}_{2}$ soil emission together with no significant difference in $\mathrm{C}$ content in total plant biomasses strongly suggested that organic cultivation stored more $\mathrm{C}$ at the level of the plant-soil system. The long-term organic cultivation (5 $\mathrm{yr}$ in the jasmine plantations) and common cultivation of jasmine accumulated 70.8 and $68.2 \mathrm{Mg} \mathrm{ha}^{-1}$ of organic $\mathrm{C}$, respectively. The long-term organic cultivation (30 yr in the tea plantations) and common cultivation of tea accumulated 71.5 and $69.4 \mathrm{Mg} \mathrm{ha}^{-1}$ of organic C, respectively.

Thus, despite the high soil $\mathrm{CO}_{2}$ emissions in the organic cultivation type, the higher soil $\mathrm{C}$ concentration strongly suggests that organic cultivation increases the sequestration of $\mathrm{C}$ and thus in turn may help mitigating climate change. Previous studies have reported similar results (Chirinda et al., 2010; Lehtinen et al., 2014). Higher soil respiration, frequently measured in organic cultivars, has been generally correlated with soil fertility, texture, higher concentrations of $\mathrm{C}$ and higher diversity and density of soil microbes and fauna (Pimentel et al., 2011; Lehtinen et al., 2014).

\section{Overall Effects of Organic Cultivation in Plant- Soil Stoichiometry, Carbon Balance, and Yield}

The higher soil C, N, P, and clay concentrations in organic plantations in tea crops are consistent with the expected positive and synergic link widely observed among organic matter concentration, clay concentration, fertility, stability, and resistance against erosion (Wagner et al., 2007; Wuddivira et al., 2009; Soinne et al., 2014). The cementing potentials of clay and organic matter are important for the stability of soil aggregates for preventing erosion and leaching (Wagner et al., 2007; Wuddivira et al., 2009; Abdollahi et al., 2014; Peng et al., 2015). Sources of organic matter improve the stability of clay aggregates and therefore improve nutrient levels and 
C-retention capacity (Soinne et al., 2014). The application of organic matter increases clay aggregation that in turn has a positive feedback on organic matter and aggregate stabilization (Djajadi et al., 2012).

These improvements in soil nutrient contents are unfortunately associated with lower yields. The average yields of jasmine flowers in the study area are 6.2 and $12.0 \mathrm{t} \mathrm{ha}^{-1} \mathrm{yr}^{-1}$ in organic and common cultivation, respectively, and the average yields of tea are 4.2 and $6.0 \mathrm{t} \mathrm{ha}^{-1} \mathrm{yr}^{-1}$, respectively. Organic cultivation has been widely associated with lower yields than the corresponding common cultivars (López et al., 2013; Yousef et al., 2015), but not all yields are lower (SeidlerLozykowska et al., 2015). The price of organic products is, however, greater than two- to threefold higher than the price of products from common cultivation. If the yield of an organic cultivation type is less than half, but the price is more than double, then total benefits will improve. Moreover, the results support organic cultivation as a very important method for improving mid- to long-term soil fertility and provide further evidence supporting the plans of Chinese government of promoting organic cultivation as a useful tool for improving the safety of crop production and for decreasing the negative environmental effects of the intensive use of inorganicindustrial fertilizers and organic compounds against pests without decreasing farmer's economy.

The higher accumulation of $\mathrm{C}$ and nutrients in the soil together with the higher clay contents suggested that the continuous use of organic cultivation instead of traditional cultivation can increase soil fertility and improve production capacity for the mid-term. Studies in other cropland systems have reported that soil fertility, soil C, and nutrient concentrations and even yield have continuously increased after several years of applying organic fertilizers under organic cultivation (Rasool et al., 2007; Zingore et al., 2008). Our results are consistent with the premise that organic cultivation will be important for the future development of sustainable agriculture in China. However, the continuous use of organic cultivation improved soil nutrient contents but decreased yield and some plant nutrient concentrations (particularly in Jasmine plants). The effect of supplementation with industrial fertilizer after several years of strictly organic cultivation should thus be investigated. The most logical hypothesis would be that the improved soil conditions after years of organic cultivation would favor a better use of moderate amounts of nutrients from industrial fertilizers and would thus improve yields.

\section{CONCLUSIONS}

Organic cultivation affects soil texture under tea but not under jasmine crops.

Soil total $\mathrm{N}$ and $\mathrm{P}$ concentrations are higher under organic cultivation in both studied species.

Organic cultivation shifted P from plants to soil in tea crops, whereas in jasmine crops this was not observed.

Jasmine plants under organic cultivation presented higher $\mathrm{C} / \mathrm{P}$ ratios, so $\mathrm{P}$-use efficiency increased, and the contrary was observed in tea crops. Differently, both cropland species presented higher $\mathrm{C} / \mathrm{N}$ ratios under organic cultivation and thus $\mathrm{N}$-use efficiency increased in them both.
The increase in $\mathrm{C}$ stored in soil in both crop types, together with the nonsignificant decrease in the $\mathrm{C}$ stored in plant biomass, suggest that organic cultivation is able to increase $\mathrm{C}$ fixation, despite the increase in soil respiration associated with organic cultivation.

The lower accumulation of $\mathrm{P}$ in biomass of Jasmine plants under organic cultivation was not associated with a decrease in biomass; instead it was related with a great decrease $(50 \%)$ of flowers production, suggesting a decoupling between vegetative and reproductive productivity

The results gave consistent support to the fact that organic cultivation is a very important method for improving mid- to long-term soil fertility without decreasing farmer's economy.

\section{ACKNOWLEDGMENT}

This work was supported by grants from the National Science Foundation of China (41571287; 31000209), Natural Science Foundation Key Programs of Fujian Province (2014R1034-3, 2014Y0054 and 2014J01119), Science and Technology Program of Fuzhou City (2014-G-66), European Research Council Synergy grant ERC-SyG-2013-610028 IMBALANCE-P, European FP7-ENV ECLAIRE project, Spanish Government grant CGL2013-48074-P and Catalan Government project SGR 2014-274.

\section{REFERENCES}

Abdollahi, L., P. Schjonning, S. Elmholt, and L.J. Munkholm. 2014. The effects of organic matter application and intensive tillage and traffic on soil structure formation and stability. Soil Tillage Res. 136:28-37. doi:10.1016/j.still.2013.09.011

AQSIQ. 2014. General administration of quality supervision, inspection and quarantine of the People's Republic of China, Beijing. Export2Asia. http://www.export2asia.com/blog/aqsiq/ (accessed 11 Apr. 2016).

Askegaard, M., J. Eriksen, and J.E. Olesen. 2003. Exchangeable potassium and potassium balances in organic crop rotations on a coarse sand. Soil Use Manage. 19:96-103. doi:10.1079/ SUM2002173

Blaise, D., T.R. Rupa, and A.N. Bonde. 2004. Effect of organic modern method of cotton cultivation on soil nutrient status. Commun. Soil Sci. Plan. 35:1247-1261. doi:10.1081/CSS-120037543

Blank, R.R. 2010. Effect of temperature on potassium and sodium exchange in a Sierra Nevada ripariam soil. Soil Sci. Soc. Am. J. 74:105-106. doi:10.2136/sssaj2009.0159N

Chirinda, N., J.E. Olesen, J.R. Porter, and P. Schjonning. 2010. Soil properties, crop production and greenhouse gas emissions from organic and inorganic fertilized-based arable cropping systems. Agric. Ecosyst. Environ. 139:584-594. doi:10.1016/j. agee.2010.10.001

Cofie, O.O., and J. Pleysier. 2004. Ion exchange involving potassiumcalcium and magnesium-calcium in soil and organic fractions. Com. Soil Sci. Plant Anal. 35:2417-2431. doi:10.1081/LCSS-200030322

Del Amor, F.M., A. Serrano-Martínez, I. Fortea, and E. NúñezDelicado. 2008. Differential effect of organic cultivation on the levels of phenolics, peroxidase and capsidiol in sweet peppers. J. Sci. Food Agric. 88:770-777. doi:10.1002/jsfa.3140

Deng, J.P., Q. Wan, and Y.G. Sun. 2010. Analysis and evaluation on soil environment quality influenced by organic rice planting in Xinjiang. Environ. Sci. Manag. 35:138-140.

Djajadi,D., L.K.Abbott, and C.Hinz.2012. Synergistic impacts of clay and organic matter on structural and biological properties of a sandy soil. Geoderma 183-184:19-24. doi:10.1016/j.geoderma.2012.03.012 
Hallmann, E. 2012. The influence of organic and concentional cultivation systems on the nutritional value and content of bioactive compounds in selected tomato types. J. Sci. Food Agric. 92:2840-2848. doi:10.1002/jsfa.5617

Hargreaves, J.C., A.M. Sina, and P.R. Warman. 2008. The effects of organic and conventional nutrient amendments on strawberry cultivation: Fruit yield and quality. J. Sci. Food Agric. 88:26692675. doi:10.1002/jsfa.3388

Lehtinen, L., N. Schlatter, A.M. Baumgarten, L. Bechini, J. Kruger, C. Grignani et al. 2014. Effect of crop residue incorporation on soil organic carbon and greenhouse gas emissions in European agricultural soils. Soil Use Manage. 30:524-538. doi:10.1111/ sum. 12151

Lin, X.B., Y.Y.Yan, Q.W. Min, J.F. Wang, J.M.Zheng, Y.X.Zhang, and W.Q. Wang. 2014. Evaluating the non-use value of agricultural heritage across Jasmine planted and tea cultural systems in Fuzhou. Resour. Sci. 36:1089-1097.

Lombardo, S., G. Pandino, and G. Mauromicale. 2012. Nutritional and sensory characteristics of "early" potato cultivars under organic and conventional cultivation systems. Food Chem. 133:1249-1254. doi:10.1016/j.foodchem.2011.10.005

López, A., J. Fenoll, P. Hellin, and P. Flores. 2013. Physical characteristics and mineral composition of two pepper cultivars under organic, conventional and soil less cultivation. Sci. Horti. 150:259-266. doi:10.1016/j.scienta.2012.11.020

Lu, R.K. 1999. Analysis methods of soil science and agricultural chemistry. Agric. Sci. and Technol. Press, Beijing.

Mishra, U., D.A.N. Ussiri, and R. Lal. 2010. Tillage effects on soil organic carbon storage and dynamics in Corn Belt of Ohio USA. Soil Tillage Res. 107:88-96. doi:10.1016/j.still.2010.02.005

Peng, X., X. Yan, H. Zhou, Y.Z. Zhang, and H. Sun. 2015. Assessing the contributions of sesquioxides and soil organic matter to aggregation in an Ultisol under long-term fertilization. Soil Tillage Res. 146:89-98. doi:10.1016/j.still.2014.04.003

Pimentel, M.S., H. De-Polli, A.M. de Aquino, M.E.F. Correira, and J.R.S. Rouws. 2011. Biondicators of soil quality in coffee organic cultivation systems. Pesqi. Agropecu. Bras. 46:546-553.

Qian, J.Q. 2011. New ideas to accelerate the revitalization of Fuzhou Jasmine Tea. Tea Fujian 33:41-43.

Raamsdonk, L.M., B. Teusink, D. Broadhurst, N.S. Zhang, A. Hayes, M.C. Walsh et al. 2001. A functional genomics strategy that uses metabolome data to reveal the phenotype of silent mutations. Nat. Biotechnol. 19:45-50. doi:10.1038/83496

Rasool, R., S.S. Kukal, and G.S. Hira. 2007. Soil physical fertility and crop performance as affected by long term application of FYM and inorganic fertilizers in rice-wheat system. Soil Tillage Res. 96:64-72. doi:10.1016/j.still.2007.02.011

Ren, H.C., X.B. Lin, C. Wang, W.Q. Wang, Q.W. Min, Y.X. Zhang, and J.M. Zheng. 2015. A study of the residents' cognition and attitudes towards the protection of agricultural heritage system from the place identity perspective: A case study of Fuzhou Jasmine and Tea Cultural System. Acta Ecol. Sin. 35:6808-6813.
Ren, H.C., Q.W. Min, W.Q. Wang, C. Wang, and Y.X. Zhang. 2014. Concentration of aero-anion and its influence factors in different habitats of Gushan tea garden, Fuzhou. Urban Environ. Urban Ecol. 27:1-6.

Seidler-Lozykowska, K., R. Mordalski, D. Krol, J. Bocianowski, and E. Karpinska. 2015. Yield and quality of sage herb (Salvia officinalis L.) from organic cultivation. Biol. Agric. Hortic. 31:53-60. doi:1 $0.1080 / 01448765.2014 .966323$

Soinne, H., J. Hovi, P. Tammerorg, and E. Turtola. 2014. Effect of biochar on phosphorus sorption and clay soil aggregate stability. Geoderma 219-220:162-167. doi:10.1016/j.geoderma.2013.12.022

Wagner, S., S.R. Cattle, and T. Scholten. 2007. Soil-aggregate formation as influenced by clay content and organic-matter amendment. J. Plant Nutr. Soil Sci. 170:173-180. doi:10.1002/ jpln.200521732

Wang, W.Q., C. Tong, and C.S. Zeng. 2010. Stoichiometry characteristics of carbon, nitrogen, phosphorus and anaerobic carbon decomposition of wetland soil of different texture. China Environ. Sci. 30:1369-1374.

Wang, X.M., D.P. Zeng, L.H. Zhang, J.H. Yan, W.Q. Wang, and H.C. Ren. 2014. Value assessment of ecosystem service function of tea plantations in Gushan Mountain of Fuzhou. Subtrop. Agric. Res. 10:156-163.

Wassmann, R., H.U. Neue, C. Bueno, R.S. Lantin, M.C.R. Alberto, L.V. Buendia et al. 1998. Methane production capacities of different rice soil derived from inherent and exogenous substrates. Plant Soil 203:227-237. doi:10.1023/A:1004357411814

Wuddivira, M.N., R.J. Stone, and E.I. Ekwue. 2009. Clay, Organic matter, and wetting effects on splash detachment and aggregate breakdown under intense rainfall. Soil Sci. Soc. Am. J. 73:226232. doi:10.2136/sssaj2008.0053

$\mathrm{Xu}, \mathrm{C} . \mathrm{T} .2012$. Industry research report of Fuzhou Jasmine Tea. Chin. Hortic Abstr. 28:24-27, 12.

Xu, G.Q., S.H. Fang, and T. Xia. 2001. Advances of Jasmine Tea processing technology. Tea Fujian 23:10-12.

Yang, J.F., T.L. Fu, N.X. Ye, Q. Chen, N.H. Zheng, Y. Sun et al. 2008. Fujian Jasmine tea. Xiamen: Xiamen Univ. Press, Xiamen, China. p. 55-57.

You, Z.M., Z.D. Wu, F.Y. Jiang, F. Wang, Y.X. Wang, L. Zhang, and B.Q. Weng. 2013. Soil respiration characteristics of 3-year-old tea garden from red soil region in south China. J. Trop. Subtrop. Bot. 21:193-202.

Yousef, E., C. Lampei, and K. Schmid. 2015. Evaluation of cauliflower gene bank accessions under organic and conventional cultivation in Southern Germany. Euphytica 201:389-400. doi:10.1007/ s10681-014-1225-y

Zingore, S., R.J. Delve, J. Nyamangara, and K.E. Giller. 2008. Multiple benefits of manure: The key to maintenance of soil fertility and restoration of depleted Sandy soils on African smallholders farms. Nutr. Cycling Agroecosyst. 80:267-282. doi:10.1007/ s10705-007-9142-2 